2. To: (Receiving organization)

Distribution

5. Proj./Prog./Dept./Div.:

WICS

8. Originator Remarks:

None.

11. Receiver Remarks:
3. From: (Originating Organization)

Data Automation Engineering and Services

6. Cog. Engr.:

W. R. Markillie
4. Related EDT No.:

$$
\mathrm{N} / \mathrm{A}
$$

7. Purchase Order No.:

$N / A$

9. Equip./Component No.:

$\mathrm{N} / \mathrm{A}$

10. System/Bldg./Facility:

$N / A$

12. Major Assm. Dwg. No.:

$\mathrm{N} / \mathrm{A}$

13. Permit/Permit Application No.:

$\mathrm{N} / \mathrm{A}$

14. Required Response Date:

$\mathrm{N} / \mathrm{A}$

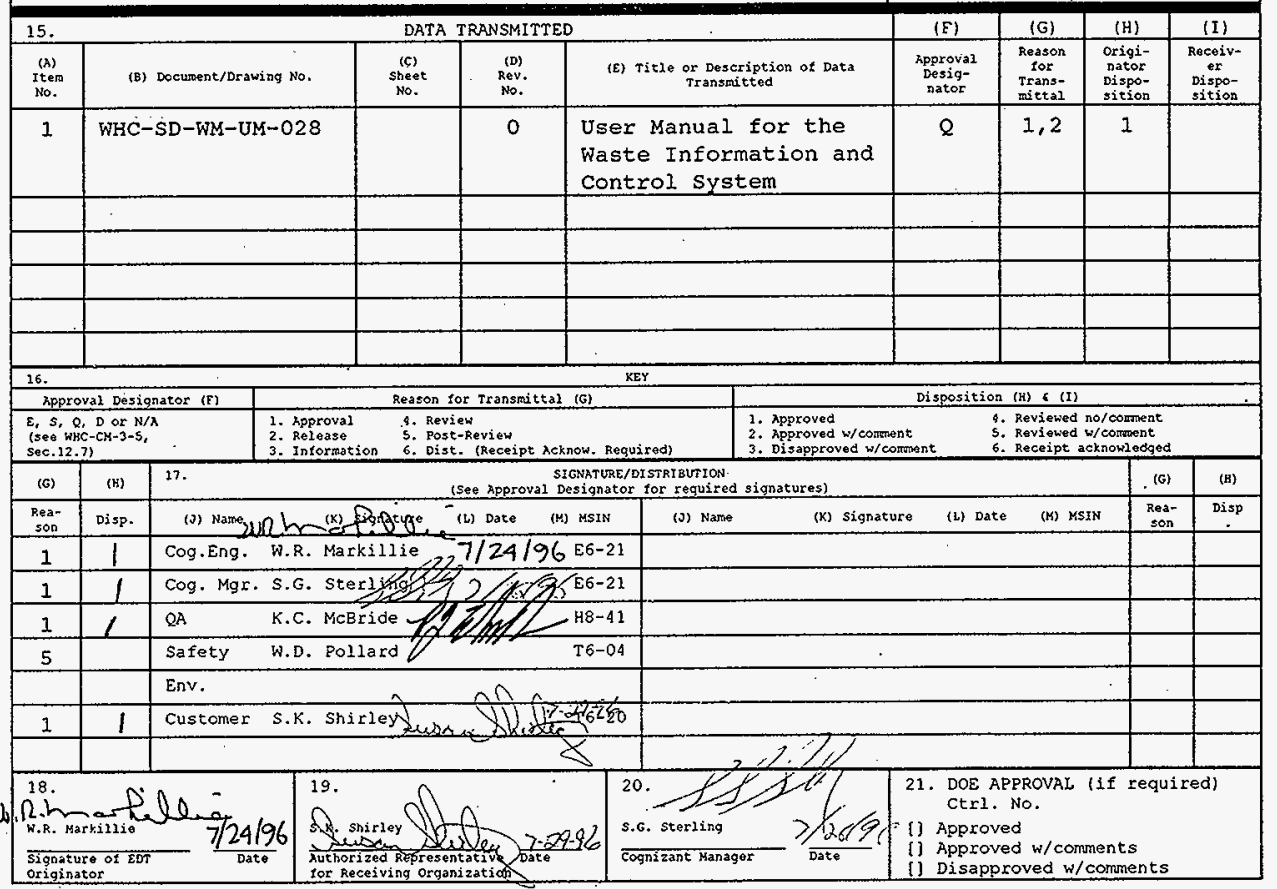




\section{User Manual for the Waste Information and Control System}

W.R. Markillie

ICF Kaiser Hanford, Richland, WA 99352

U.S. Department of Energy Contract DE-AC06-87RL10930

$\begin{array}{llll}\text { EDT/ECN: } & 615546 & \text { UC: } 2070 \\ \text { Org Code: } & 57 \text { B00 } & \text { Charge Code: } & \text { FOG3R4 } \\ \text { B\&R Code: } & \text { EW3130030 } & \text { Total Pages: } & 22\end{array}$

Key words:

WICS

Waste Information Control system

uM

Abstract: This document describes the user instructions for the wICs application.

TRADEMARK DISCLAIMER. Reference herein to any specific comnercial product, process, or service by trade name, trademark, manufacturer, or otherwise, does not necessarily constitute or imply its endorsement, recommendation, or favoring by the United States Government or any agency thereof of its contractors or subcontractors.

Printed in the United States of America. To obtain copies of this document, contact: WHC/BCS Document Control Services, P.0. Box 1970. Mailstop H6-08, Richland WA 99352, Phone (509) 3722420; Eax (509) 376-4989.

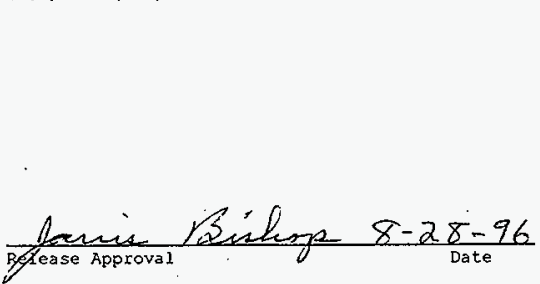

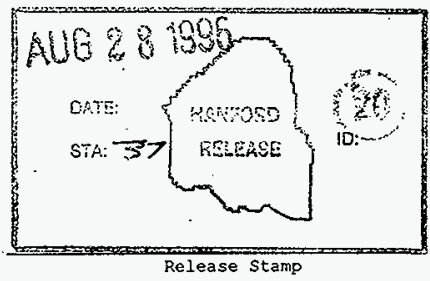

Approved for Public Release 


\section{USER MANUAL}

FOR THE

\section{WASTE INFORMATION AND CONTROL SYSTEM}

June 1996

Prepated by:

ICF Kaiser Hanford

Data Automation Engineering

Prepared for:

Westinghouse Hanford Company

P.O. Box 1970

Richland, Washington 99352 
UNCLASSIFIED

WHC-SD-WM-UM-028

Revision 0

Page 2

\section{TABLE OF CONTENTS}

Section

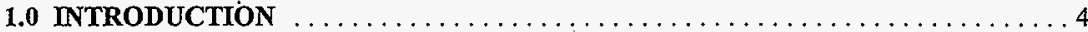

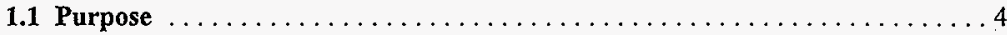

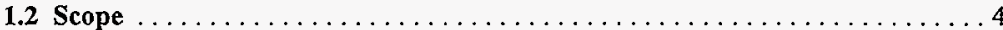

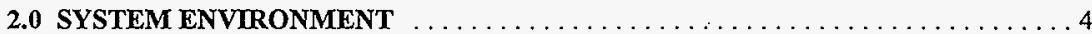

2.1 Minimum System Requirements $\ldots \ldots \ldots \ldots \ldots \ldots \ldots \ldots \ldots \ldots \ldots$

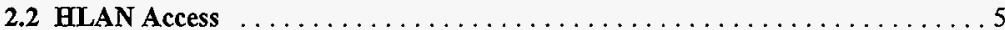

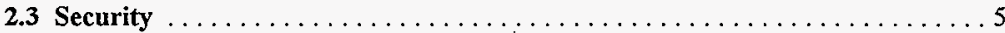

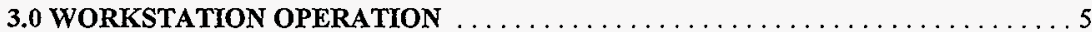

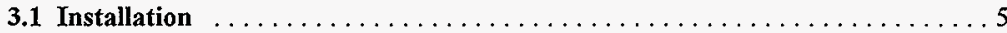

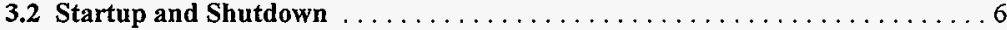

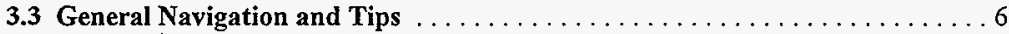

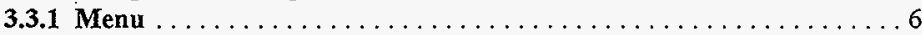

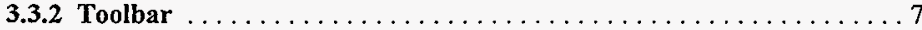

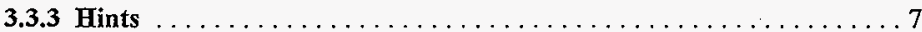

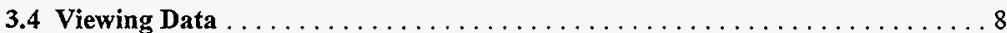

3.4.1 Folders $\ldots \ldots \ldots \ldots \ldots \ldots \ldots \ldots \ldots \ldots \ldots \ldots \ldots \ldots$

3.4.2 Drop-Down List Definitions $\ldots \ldots \ldots \ldots \ldots \ldots \ldots \ldots \ldots$

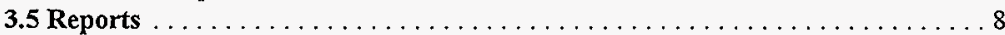

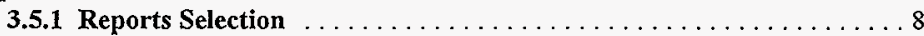

3.5.2 Report Destination . . . . . . . . . . . . . . . . . . 9

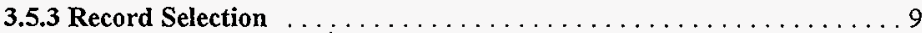

3.5.4 Previewing Reports $\ldots \ldots \ldots \ldots \ldots \ldots \ldots \ldots \ldots \ldots \ldots$

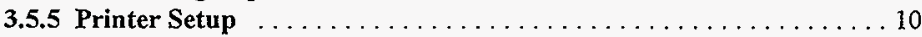

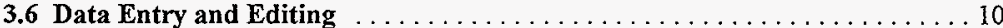

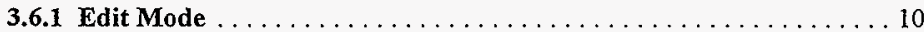

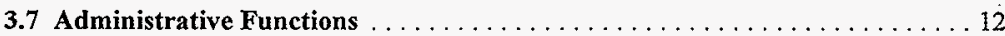

3.7.1 Master Data ............................. 12

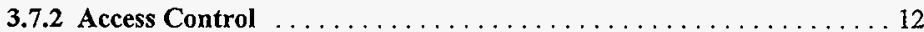

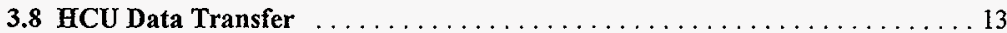

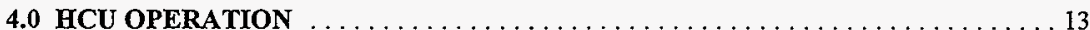

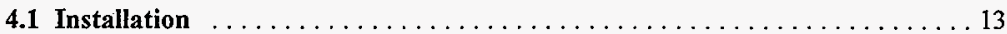

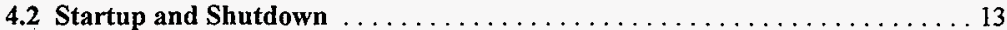

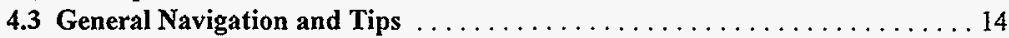

4.4 Data Entry and Editing ............................ 14 
UNCLASSIFIED

WHC-SD-WM-UM-028

Revision 0

Page 3

4.5 Transferring of Data 14

5.0 ERROR MESSAGES

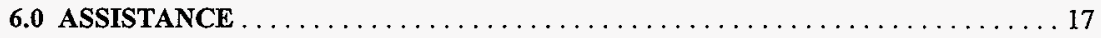

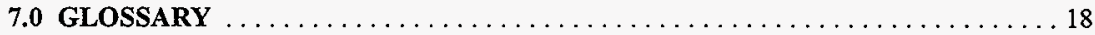

8.0 PROBLEM/ENHANCEMENT FORM $\ldots \ldots \ldots \ldots \ldots \ldots \ldots \ldots \ldots \ldots \ldots \ldots \ldots$ 


\section{USER MANUAL FOR THE \\ WASTE INFORMATION AND CONTROL SYSTEM}

\subsection{INTRODUCTION}

\subsection{Purpose}

This manual is intended to provide users with enough detailed instruction to guide them through the Waste Information and Control System (WICS) operations.

\subsection{Scope}

This document satisfies the requirement for user documentation as stated in the WICS Work Plan WHC-SD-WM-WP-269. It is intended to provide detailed instructions regarding use of the available functions of the Waste Information and Control System (WICS). The user manual shall include system environment requirements, limited equipment operation instructions, and system operation instructions.

This document does not provide detail regarding the system requirements, system design, or testing procedures of the WICS. Nor does it make reference to any specific data.

\subsection{SYSTEM ENVIRONMENT}

\subsection{Minimum System Requirements}

The WICS minimum hardware requirements are as follows:

- 386 or higher IBM-Compatible Personal Computer (PC), 486 is recommended.

- $\quad$ A hard disk drive configured as " $\mathrm{C}:$ ".

- An available serial port for HCU communications.

- At least 8 megabytes of RAM

- At least 30 megabytes free disk space on "C:".

- Hanford End System Operating Environment (ESOE). 
UNCLASSIFIED

WHC-SD-WM-UM-028

Revision 0

Page 5

\subsection{HLAN Access}

The WICS needs to utilize PC hardware that is End System Operating Environment (ESOE'd) and utilizes the Hanford Local Area Network (HLAN). The system also needs to have access to a LaserJet III or compatible printer connected either locally or via the network.

\subsection{Security}

The WICS shall be installed on authorized user machines only. Security access for passwords and privileges are assigned and is the responsibility of the system administrator.

\subsection{WORKSTATION OPERATION}

\subsection{Installation}

The WICS application, hereafter referred to as WICS, can be installed by following instructions provided by a README.TXT file that the current WCS system administrator will provide. Since this application runs on the HLAN, it is susceptible to inoperability due to network problems. Section 6.0, Assistance, discusses the contacts for system support.

Before starting the installation process, ensure that the minimum system requirements are being utilized. Read the README.TXT file thoroughly and print it out for reference during installation.

Following the README.TXT instructions will set up a Windows Program Group entitled "WICS Phase 1" consisting of the following icons: Installer, WICS, Readme, and a Change Log.

When double clicked, the "Installer" icon will initiate the "Effortless Software Distribution" with several WICS application choices for installation. If WICS is being reinstalled, select "WICS"; this is the production version. Continue to follow the instructions required to exit the window. The installation program may suggest a restart of the computer when the install is complete. This is only necessary if the application is being installed for the first time.

When finished, double click on the "WICS" icon to launch the application; select the user name and password that was assigned by the WICS System Administrator. To access the application as a "Read Only" user, select that name in lieu of a user name and enter no password. Section 3.2, Startup and Shutdown, discusses how to logon and logoff WICS.

The Readme icon displays a file that contains information that was provided by the WICS System Administrator to begin this process. In addition to installation help, it also provides useful 
information on configuring a computer for better performance. The Change $\log$ is an automated notebook that logs WICS application functionality changes for reference and information.

\subsection{Startup and Shutdown}

\section{STARTUP}

First, launch the WICS application by double clicking on the WICS icon. When the logon dialog appears, select the appropriate name from the drop-down list or type the name exactly as it appears on the drop-down list and provide the password. If a user just wants to view the WICS data, and perform no editing, then select the Read Only name in lieu of a user name and enter no password. Upon correct entry of their name and assigned password, the application is displayed. If either the name or password is entered incorrectly the user is given an option to try again.

The application's pull-down menu consists of the following areas: Inner Container, Outer Container, HCU, Reports, Master Data, Help, and Exit. When a user has selected to any of these areas and the text cursor is flashing on an active field, it is referred to as in "focus". Focus is where the text cursor is located, not necessarily where the mouse pointer is located. Focus can also be changed by using the tab and shift-tab keys or clicking on any object or field that can assume focus.

\section{SHUTDOWN}

To log off WICS, the user can either select from the main menu "Exit" option or double-click the system menu icon. Once exit is initiated, select "Yes" to continue with the exit and the system will return to Windows.

\subsection{General Navigation and Tips}

\subsubsection{Menu}

The pull-down menu options are located at the top of the window. The options are: Inner Container, Outer Container, HCU, Reports, Master Data, Help, and Exit. Many of these options have a pull-down menu that can be initiated by selecting an option with the arrow and pressing the left side of the mouse. Selection is made by highlighting the choice and releasing the left side of the mouse. When menu options appear as "grayed-out" (instead of sharp black) they are either not available for that privilege or that function is currently in use. Some menu options have an associated function key or keys that, when pressed, invokes the same operation. The keystroke alternatives are typically identified to the right of the menu item title. Also, functions typically have an underlined letter somewhere in the menu option title. To initiate these functions press the ALT key and the underlined letter key simultaneously. 


\subsubsection{Toolbar}

The toolbar is located below the pull-down menu options. The toolbar consists of icons and navigation buttons. Functions represented by icons can be initiated when clicked. The icons remain present and are operable throughout various forms. The navigation buttons are used for the different forms and folders when moving about records. The icons present will depend upon functions available in context with the view and user privileges. Below are the icons and navigation buttons in the order as they appear on the toolbar:

\begin{tabular}{ll} 
| < navigation button: & Moves to the first record. \\
< navigation button: & Moves to the prior record. \\
\hline navigation button: & Moves to the next record. \\
\hline | navigation button: & Moves to the last record. \\
Plus Sign button $:$ & Inserts a new record. \\
Minus Sign button: & Deletes a record and all associated data. \\
Triangle button: & Enables edit mode for the current record. \\
Checkmark button: & Posts the record's data entry to that point. \\
Crossout button: & Cancels an edit, if entry has not been posted. \\
Swirl Arrow button: & Refreshes the screen with newly posted entries. \\
Copy Record icon: & Copies the current record.
\end{tabular}

\subsubsection{Hints}

The hint boxes are yellow boxes below certain controls and fields that give a text descriptor. When the mouse pointer is placed over an object for one second, the hint box appears. It is removed when the mouse pointer is repositioned. 
UNCLASSIFIED

WHC-SD-WM-UM-028

Revision 0

Page 8

\subsection{Viewing Data}

Upon entering any form, the mode is always view, unless the user has placed the current record in another state (Insert or Edit). If a field has focus, any keystroke shall automatically place the current record in edit mode. Changes are saved when the Checkmark button is pressed, or when the user attempts to move off of the current record.

\subsubsection{Folders}

There are several Folders available throughout WICS with each Folder having a tab for ease of selection. Each Folder contains different data associated with WICS. For example, the Chemical Component Folder on the Inner Container Logbook Form has information regarding chemical components for the current inner container.

\subsubsection{Drop-Down List Definitions}

To the right of some fields there will be a boxed "down arrow". When clicking on the "down arrow" a drop-down list will appear. The drop-down lists will display the mandatory selections for data entry purposes; an entry must be from this list. The exception is the Procedure Number field located in the Inner Container Logbook. The pull-down list for Procedure Number provides standard procedure numbers only. The user may type a different procedure number if the desired one does not exist in the list. If a field has no boxed "down arrow" to the right, then data entry is made from the keyboard and is limited only to the data type of that field (e.g., integer, alphanumeric, etc.).

The drop-down list definitions are viewable when selecting from the pull-down menu "Master Data". The list definitions are updated by the System Administrator and are viewable to all privileges. The navigation buttons function the same as those used on the toolbar. However, the edit control buttons are different for non-administrator privileges than they are for administrator privileges.

\subsection{Reports}

To get into the Report mode, select from the pull-down menu "Reports". This will present the Report form.

\subsubsection{Reports Selection}

There are many types of reports that can be printed in WICS. To select a report, choose the desired report from the drop-down list titled, "Select a Report". 
For some reports, a list of available records shall appear with navigation buttons and a "Chosen" list. In order to select which records are desired for the report output, use the navigation buttons (i.e., $>,<>>$, or $<<$ ) to move the records to the "Chosen"/Print List. See section 3.5.3, Record Selection.

Other reports shall prompt the user to input valid information. For example, the Disposal Request Report requires the user to enter a HMC Letter Number along with selecting specific records.

\subsubsection{Report Destination}

Once the desired records have been moved to the "Chosen"/Print List, a report destination must be selected. A report can be sent to the screen, or to the printer. Regardless of the destination, the "Print" button must be clicked for the report to be generated and the "Preparing Report..." message will be displayed.

If sending a report to the printer, after the report has been prepared, the reports will print out. Some reports require legal size paper, check the "Print Manager" option in Windows if a problem arises.

Sending a report to the screen is discussed in section 3.5.4., Previewing Reports.

\subsubsection{Record Selection}

Records can be selected from the "Available" list for inclusion on the "Chosen"/ Print List. In order to select which records are desired for the report output, use the navigation buttons (i.e., >, $<,>>$, or $<<$ ) to move the records to the "Chosen"/Print List area.

As mentioned, when all parameters are selected, click the "Print" button. A "Preparing Report..." message will be displayed while the required data is retrieved.

\subsubsection{Previewing Reports}

A user can preview their reports on the screen as mentioned above by selecting "Screen". Once the report is available on the screen, it can be viewed by the navigation buttons located at the top of the screen. These icons and navigation buttons are as follows:

Positive Magnifying button: Zooms in the report by ten percent.

Negative Magnifying button: Zooms out the report by ten percent.

Half sheet paper button: Displays report at full width. 

Full sheet paper button:
Fits report in window.
$<$ navigation button:
Moves to the prior page.
$>$ navigation button:
Moves to the next page.
Printer Setup button:
Initiates the Windows printer setup dialog box.
Printer button:
Initiates a print of the report shown.
Door Close button:
Closes the report preview.
Zoom \%:
Zooms to the user-defined percent.
Page:
Moves to the user-defined page.
Page of Page:
Denotes page number of how many pages are in the report.

\subsubsection{Printer Setup}

In order to set network and non-network printers click the "Printer Setup" button from the Reports screen or the Print Preview screen. This will enable a user to make appropriate selections based upon the need of the report output.

\subsection{Data Entry and Editing}

\subsubsection{Edit Mode}

To start an edit session, the user can 1) click the triangle (edit) button from the toolbar, or 2) set. focus on an editable field and begin data entry. To post changes, click the Checkmark button from the toolbar, or attempt to move to a new record. The Cancel button will disregard any changes to the current record and place the record in view mode. Changes can be cancelled only before posting them.

User privileges are required for editing each of the different screens. If a user does not have privileges for a screen, the editing control buttons will not be visible.

Data may only be input into focus areas on the form. As mentioned, focus is where the text cursor is located, not necessarily where the mouse pointer is located. Focus can also be changed by using the tab and shift-tab keys. 
If the focus is within a table (Chemical Components, et. al.) with a vertical slider bar (consisting of a boxed up and down arrow in a rectangle with slider), this implies that a user may enter more than one set of data or record. To enter more than a single data set, press the "Insert" key on the keyboard or click on the Insert button on the toolbar. This will prompt for a new data set. Or use tab at the last entry of a table to create a new entry.

WICS data entry is performed via; 1) input from the keyboard, 2) selection from drop-down lists, or from 3) data transferred from the HCU. Checks are performed on the data entered to ensure consistency. The toolbar also has icons for data entry:

Plus Sign button : Inserts a new record.

Minus Sign button: $\quad$ Deletes a record and all associated data.

Triangle button: $\quad$ Places the current record in Edit mode.

Checkmark button: Posts the record's data entry to that point.

Crossout button: $\quad$ Cancels an edit, if entry has not been posted.

Swirl Arrow button: $\quad$ Refreshes the screen with newly posted entries.

Inserting, editing and deleting of any data requires a privilege other than readonly.

Inserting a Record

To insert a new record, the user must select the Plus Sign icon. When this option is selected, the different fields on the current screen are presented blank ready for data entry. The user should fill in the data for each of the focus areas, but is not mandatory.

Deleting a Record

To delete the current record, the user must select the Minus Sign icon. A "Warning" message is presented so a user can select No to cancel the record deletion.

Note that a new blank record created in a table will be automatically deleted if no value is entered and the user does not focus to another field within the record. Blank records can be deleted using CTRL-DEL if necessary. 


\subsection{Administrative Functions}

\subsubsection{Master Data}

The Master Data definitions support the drop-down list information. Select from the pull-down menu "Master Data" to initiate the Definitions form. This form is available to non-administrative users and shows the drop-down lists available during all sessions (i.e, locations and origins).

If the privilege is set up for System Administrator or Limited user, then all the navigation buttons are available; if not, then the "** indicates that these buttons are available to non-administrative users for viewing this form:

$$
\begin{array}{ll}
\begin{array}{l}
\text { I< navigation button:* } \\
\text { < navigation button:* }
\end{array} & \begin{array}{l}
\text { Moves to the first entry. } \\
\text { > navigation button:* }
\end{array} \\
\text { > navigation button:* } & \text { Moves to the next entry. } \\
\text { Plus Sign button: } & \text { Starts a new entry. } \\
\text { Triangle button: } & \text { Initiates an edit. } \\
\text { Checkmark button: } & \text { Posts the entry. } \\
\text { Crossout button: } & \text { Cancels an edit, if entry has not been posted. } \\
\text { Swirl Arrow button: } & \text { Refreshes the screen with newly posted entries. }
\end{array}
$$

For data integrity purposes, master data may not be deleted from the WICS application. To compromise for this, every piece of master data has a field titled "Active" associated with it. Setting this property to "True" enables the data to be displayed in the drop-down lists. Conversely, setting the property to "False" removes the data from the drop-down lists. This setting may only be modified by a "System Administrator" or "Limited" user.

\subsubsection{Access Control}

The function(s) that a user is limited to are defined by the System Administrator. Full privileges are granted to a System Administrator, and on the other hand, the Read Only user has the most limited privileges. The following are privileges that may be assigned by the System Administrator: 
1) Read Only - View-information (except user data).

2) General - Read Only privileges plus, insert and modify Inner Container Data and Outer Container Data, Send or Receive HCU data.

3) Limited - General privileges plus, insert, modify and delete Master Data (except user data).

4) System Administrator - All functions.

The System Administrator has the authority to assign new users, passwords, and privileges. The User Information form is used to assign new users, passwords, and privileges. A user must be assigned certain privileges from a System Administrator, including the System Administrator user.

\subsection{HCU Data Transfer}

The user may choose to send or receive data from the HCU. To perform these functions, the user must select "HCU" from the pull-down menu, then select either "Send" or "Receive" depending on the desired option. A HCU must be properly seated into a cradle connected to the user's computer via a RS-232 cable. The user needs to verify the correct COM port, thus the port supporting the HCU cradle, is displayed on the HCU Send or Receive screen, and click the "OK" button. If the COM port is not correct, the user may change the value by simply entering the correct one.

Once the user has clicked the "OK" button on the workstation, the data transfer option on the HCU must be started. This is done by choosing either the "Configure Unit" option in conjunction with the "Send" option on the workstation, or the "Transfer Data" option in conjunction with the "Receive" option on the workstation. See Section 4.0 "HCU Operation" for more information regarding operation of the $\mathrm{HCU}$.

Once the HCU data transfer is complete, the screen displayed on the workstation shall provide the user with information regarding the status of the transferred files.

\subsection{HCU OPERATION}

\subsection{Installation}

The installation of WICS on the HCU is permanent. Upgrades and changes must be performed by the WICS development team.

\subsection{Startup and Shutdown}

The HCU may be started by simply pressing the "PWR" key. If the unit does not have a user actively logged in, a welcome screen should be visible. The user may press any key to continue. 
Next, the user shall be prompted to enter their Hanford ID, this may be performed using the keyboard or integrated scanner. Upon entering a valid $\mathrm{ID}$, the user shall be prompted to verify the date and time. After completing this step, the main menu is displayed.

Shutdown of the system is simply performed by selecting "Logon New User" from the main menu. The "PWR" key enables the user to power the system off.

\subsection{General Navigation and Tips}

The HCU is a menu-driven application, thus the user must select which function to perform via menus. The main menu offers six separate choices, Inner Container, Outer Container, Configure Unit, Transmit Data, Logon New User, and Quit. Any option may be chosen by simply pressing the key corresponding to the appropriate number displayed on the menu. At this time, the "Quit" option is unavailable, and the user must select "Logon New User" to end a data collection session.

The Inner Container option produces a sub-menu with the following choices; Label Container, Weigh Container, Sample Waste, and Quit.

The Outer Container option produces a sub-menu with the following choices; Log New CIN, Outer Inventory, and Quit.

The Configure Unit option allows the user to download the current master data from the workstation. This data is used by the HCU to produce pick-lists for the data collector.

The Transmit Data option ailows the user to send any collected data to the workstation. Once the data has been successfully sent to the workstation, it is erased from the HCU.

\subsection{Data Entry and Editing}

Data entry on the HCU is performed by using either the keyboard or integrated scanner. Alphanumeric characters may be entered via the keyboard by pressing the "ALPHA" key and the desired characters. All data is accepted when the user presses the "ENTER" key.

A data entry session may be canceled by the user by pressing the "FUNC" key followed by the " 7 " key. This shall always present the preceding menu or function.

\subsection{Transferring of Data}

Transferring of data may occur in two separate ways. First, data may be sent to the HCU from the workstation. This is referred to as "Configuring the Unit", and may be performed on the 
HCU by selecting "Configure Unit". It is initiated on the workstation by selecting HCU-Send. Each unit should be configured before a data collection session, or when the system administrator has changed the master data.

The function "Transmit Data" on the HCU sends collected data to the workstation. The function is initiated on the workstation by selecting HCU-Receive. Once data has been transferred from the HCU to the workstation, it is erased from the HCU.

Once the user starts a transfer session on the HCU, they have a limited amount of time to start the appropriate workstation function. Both the workstation and $\mathrm{HCU}$ must function at the same time, or one side shall produce an error.

\subsection{ERROR MESSAGES}

One or more of the following are error messages are presented to the user when an error has occurred in the WICS application. Italics indicate where information is substituted into the message at run time. The error messages can be closed by clicking $\mathrm{OK}$.

Accumulation Date Required:

"An accumulation date is required for this location."

This error message occurs when a user attempts to save a record that requires an accumulation date. An accumulation date is required based on the respective location. The user must modify the record or cancel the edit session.

\section{Checklist Warning:}

"The \{Checklist Name\} Checklist for this CIN has not been completed."

This error message occurs when a user attempts to complete a checklist, specified in \{Checklist Name\}, that is missing a prior checklist. For example, this error would result if the user attempted to complete the Drum Shipping checklist before completing the Drum Packing Checklist.

\section{Duplicate Entry:}

\section{"Duplicate Entry"}

This error message occurs when a user attempts to save a record that already exists. The user must modify the record or cancel the edit session. 
UNCLASSIFIED

Field Value Required:

"Field value required. Field: \{Fieldname\}"

This error message occurs when a user attempts to save a record that requires certain data. The name of the required data element is specified by \{Fieldname\}. The user must modify the record or cancel the edit session.

HCU Terminated Error:

"Terminated with Error"

This error message occurs when a user attempts to communicate with the HCU and receives an error. Possible errors are: 1) No HCU in cradle 2) Invalid COM Port 3) Poor cable connection 4) Failure to start HCU. The user must press a key to continue.

Logon form error message:

"Incorrect password, do you wish to try again?"

This error message occurs when a user attempts to logon with an incorrect password that does not correlate to their user name. Remember, a user is assigned a password by the WICS System Administrator.

No Data Warning:

"No data to report."

This error message occurs when a user attempts to generate a report that contains no data. 


\subsection{ASSISTANCE}

For assistance regarding adding/deleting a user and user privileges for the WICS application, contact the WICS System Administrator. Also, contact the WICS System Administrator for problems relating to the WICS application.

For assistance regarding the HLAN and computer resource difficulties, contact the HLAN Network Administrator, Computer Technical Support, at 376-1234.

For questions regarding the WICS application, on-line Help assistance will be available in the very near future. In the following section, 7.0 Glossary, the on-line Help assistance messages are written in a dialog easily retrievable for the various forms containing the Help button. Questions regarding the use of the WICS application should be directed to the WICS System Administrator. 


\subsection{GLOSSARY}

\section{1 st Level Help Boxes (Contents for Help)}

The Contents for Help box is the 1st level help box that will be available from the pull-down menu "Help" and will display choices as shown below.

Choices:

\section{Contents for Help}

1) About the Application

2) Adding a New Record

3) Deleting a Record

4) Editing a Record

5) $\mathrm{HCU}$

6) Master Data

7) Printing

8) Privileges

9) Reporting

Once a user has clicked on their selection, some choices will display their message, while others will bring out a new set of choices relating to the subject. Shown are the 2 nd level help boxes displaying the expected choices or message(s).

\section{2nd Level Help Boxes}

1) About the Application message:

WICS, Version XXX, Date, Data Automation Engineering and Services, (O 1996, ICF Kaiser Hanford Co. All rights reserved.

2) Adding a New Record message:

Select the Plus Sign icon. The fields are presented blank ready for data entry.

3) Deleting a Record message:

1) Locate the record to be deleted 2) select the Minus Sign icon. The user must locate the record to be deleted first because the record that WICS is located on is the record recognized to be deleted. However, a "Warning" message is presented so a user can select "No" to cancel the deletion. 
4) Editing a Record message:

To start an edit session, the user may 1) click on the "Diamond" (edit) button located on the tool bar or 2) place focus on an editable field and begin data entry. To end an edit session, click the "Checkmark" (post) button or attempt to move off of the current record.

\section{5) HCU message:}

To transfer data to the HCU, select "HCU' from the pull-down menu, then choose "Send". A dialog window shall appear prompting the user for a COM port number. Once a number is entered, the user may press the OK button to begin the transfer. The HCU must be prepared to accept data. After the transfer is complete, the window shall be updated to display information regarding success of the transfer.

To transfer data from the HCU, select "HCU" from the pull-down menu, then choose "Receive". A dialog window shall appear prompting the user for a COM port number. Once a number is entered, the user may press the OK button to begin the transfer. The HCU must be prepared to send data. After the transfer is complete, the window shall be updated to display information regarding success of the transfer.

6) Master Data message:

The drop-down list definitions support the drop-down list information. Select from the pull-down menu "Master Data" to initiate the Master Data Screen. This screen is available to non-administrative users and shows the drop-down lists available during all sessions (i.e, Limited and Read Only).

If the privilege is set up for a user with privileges other than "Read Only" then all the 'editing/inserting/deleting' navigation buttons are available. If the privilege is set up for a non-administrative user, then only the 'move record' navigation buttons are present.

7) Printing message:

In order to set network and non-network printers 1) click the "Printer Setup" button from the Reports or Report Preview screen. This will enable a user to make appropriate selections based upon a special need of the report output (i.e. different printer).

Although other options are also available when the "Printer Setup" selection is made, the page size and orientation selection does not needs to be setup for printing. Each report is already formatted for its orientation.

8) Privileges message:

The following privileges are defined:

a) Read Only - View information (except user data). 
b) General - Read Only privileges plus, insert and modify Inner Container Data and Outer Container Data, Send or Receive HCU data.

c) Limited - General privileges plus, insert, modify and delete Master Data (except user data).

d) System Administrator - All functions.

The System Administrator is the only privilege that can select the "Users" folder. The User Information form is used to assign new users, passwords, and privileges.

9) Reporting message:

Contents for Reporting Help

Choices:

a) Reports Selection

b) Record Selection

c) Previewing Reports

3rd level help boxes will show the following messages for each choice:

a) Section 3.5.1 of this User's Manual.

b) Section 3.5.3 of this User's Manual.

c) Section 3.5.4 of this User's Manual. 


\subsection{PROBLEM/ENHANCEMENT FORM}

If there are any areas in which a User sees possible improvements in WCS, send suggestions and input to the WICS System Administrator. The User should fill out the

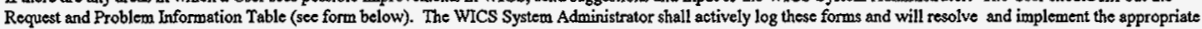
solutions.

\section{Request and Problem Information Table}

NOTE: Submitter Fills In Parts 1-8 (NON-GRAY)

1. SCR Type: [ ] Development [ ] Problem [ ] Enhancement

2. Submitted By:

3. Date:

4. Project Name:

5. Submitter's Priority [ ]

(1= Critical 2= Very Important 3= Important 4= Inconvenient $5=$ Interesting)
TOR STSTEM AOMIN USE ONUY

SCR Numbe:

Sof weare Progran Name:

TPEN $15 \%$

Cursent VetRev:

6. Requested

Completion Date:

7. Task/Change/Problem Title (One Sentence Description):

8. Detailed Description/Justification (Attach Additional Sheet If Necessary):

FOR DAES \&. SYSTEM ADMINISTRRATIOR USE ONVYT. SOftware Change Request and Problem Report Resolution Information

Becision By.

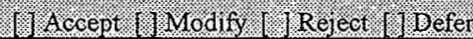

Assigned To:

Tatget Release bate:

Solution Comnentsilimpact

Softwate Programs, Wodules or Tiles Affected.

Task Completed By:

Bate:

Verified By

Bate:

Lctual Relese. Version:

Bate:

Closed By:

Date: 